\title{
La narrativa transmedia como apoyo pedagógico para la formación disciplinar de los estudiantes en la educación superior
}

\section{Transmedia Narrative as pedagogical support for disciplinary training of students in Higher Education}

Recibido: 13/08/2019

Aceptado: 04/11/2019

Publicado: 05/12/2019
Fabio Ribero Salazar fabio.ribero@usa.edu.co Universidad Sergio Arboleda (Colombia)

Harold Pérez Barrera harold.perez@unilatina.edu.co

Mauricio Rodríguez Ruíz mauricio.rodriguez@unilatina.edu.co Institución Universitaria Unilatina (Colombia)

Resumen: El artículo es el resultado de un proyecto de investigación, realizado dentro del entorno de la Educación Superior en la ciudad de Bogotá, mediante la aplicación y desarrollo de estrategias transmedia, como herramienta de construcción, respuesta y apropiación del conocimiento dentro del entorno académico. Por lo tanto, se presentan los procesos desarrollados a lo largo de la investigación y demuestra cómo la transmedia puede ser una herramienta útil en el quehacer pedagógico de los docentes. Este estudio está respaldado en un análisis teórico que, desde el campo de la educomunicación, muestra la estrecha relación que existe entre los medios, la pedagogía y la comunicación y cómo se relacionan con las TIC y los avances tecnológicos. 
Palabras clave: Educomunicación, Transmedia, Didácticas pedagógicas, Tecnología educativa.

Abstract: The paper is the result of research, carried out within the environment of higher education in the city of Bogotá, through the application and development of Transmedia strategies, as a tool for construction, response and appropriation of knowledge within the academic environment. Therefore, the processes developed throughout the research are presented and demonstrates how transmedia can be a useful tool in the pedagogical work of teachers. This study is supported by a theoretical analysis that from the field of educommunication, shows the close relationship that exists between the media, pedagogy and communication and how they relate to ICTs and technological advances.

Key words: Educommunication, Transmedia, Pedagogical didactics, Educational technology.

\section{Introducción}

Las actuales dinámicas de la educación universitaria en Latinoamérica demuestran, cada vez más, la importancia de incorporar, en el aula de clase, contenidos que fomenten en los estudiantes una mayor apropiación del conocimiento, mediante el cambio sustancial de las tradicionales cátedras jerarquizadas, que no permiten crear escenarios de disertación y análisis de los conocimientos $\mathrm{y}$, por el contrario, sólo es el espacio para la transmisión de información. De esta forma, se vienen articulando procesos innovadores que les permita a los docentes y estudiantes generar mejores espacios de interacción en el aula de clase, a través de la generación de contenidos aplicados a los medios de comunicación que se vienen incorporando en el salón.

Desde hace algún tiempo se viene trabajando el concepto de educomunicación, como mecanismo de integración de los diferentes componentes que se ven explícitos en el aula de la clase y que permiten generar esa interacción entre los actores que se ven representados en el proceso educativo. No se trata solamente de reconocer la didáctica como elementos sustanciales del componente pedagógico, sino de reconocer a la comunicación como ingrediente indispensable para el desarrollo del trabajo educativo de las instituciones de educación superior. 
Cuando tratamos de usar y articular estas dos ciencias (comunicación y educación) que se encuentran necesariamente unidas, se piensa que ninguna complementa a la otra: cuando se informa, no se educa y cuando se enseña da igual si la comunicación es asertiva. Paulo Freire, citado por Martín-Barbero (2000), explica la necesidad de elaborar y construir lenguajes que permitan, dentro del aula de clase, generar una verdadera apropiación del conocimiento en un tejido social, es decir, que sea aplicable y fundamental para el desarrollo del individuo en un contexto determinado de la sociedad.

Es lo que Freire llama "palabra generadora" que no es más que la inercia que el lenguaje puede hacer por el individuo, en un momento que está condicionado a recibir y construir conocimiento. Y esto lo que precisamente dice la pedagogía cuando se refiere a la importancia de la palabra para la acción: "La importancia del silencio en el espacio de la comunicación es fundamental [...] permite, por un lado, escuchar el habla comunicante de alguien, como sujeto y no como objeto, entrar en el movimiento de su pensamiento volviéndome lenguaje" Martín-Barbero (2000).

De aquí la importancia del lenguaje en un proceso de educación, no solo por lo que se transmite, sino por lo que no se transmite de forma explícita: los diferentes estados de actitud frente al mensaje, donde intervienen las distintas estructuras de conocimiento que se ven involucradas en el proceso de educación. Martín Barbero (2000) hace hincapié en el contexto del individuo y la importancia de lo que las personas leen e interpretan en el mensaje desde su lugar de enunciación. Cada persona interpreta y lee el mundo según a lo que referencia del pasado, gracias a la información mediatizada por diferentes organizaciones sociales que definen las propuestas incorporadas desde la acción que son definidas desde la palabra.

Desde la década de los setentas, Martín-Barbero (2000) sostiene la posibilidad de estudiar y analizar los elementos que intervienen e influyen dentro del mensaje. En esa línea, comenzó a identificar la influencia de la comunicación dentro del entorno educativo desde el emisor (“dominador") y el receptor ("dominado"), quien es seducido por las diferentes estimulaciones al momento de establecerse una relación cómplice entre ambos.

Las relaciones entrelazadas entre el lenguaje y la acción son desarrolladas básicamente con el objetivo de determinar el nivel de cada una de las estructu- 
ras y el grado de motivación, que se identifica gracias al estímulo propuesto. Esta relación tácita del fenómeno comunicativo implica la generación de una experiencia originaria del hombre y su conformación como sujeto activo y pasivo, influenciado por la mediación, el lenguaje y la interacción.

\section{Los nuevos lenguajes en la sociedad digital}

Varios autores han definido a la era contemporánea como la "sociedad de la información". Esta se define como una estructura social que basa su desarrollo en la información o en lo que Castells (1999) denomina "informacionalismo", cuyas principales fuentes de productividad son "la generación del conocimiento, el procesamiento de información y la transmisión de símbolos” (p. 120). Ese proceso surge de la conexión entre comunicación, cultura y economía, dado que la base de muchas dinámicas sociales y económicas es la información.

Para Havelock, citado por Castells (1999), esta era es crucial, como lo fue la Antigüedad (con el surgimiento de la escritura hace miles de años) o el Renacimiento (aparición de la imprenta), dado que

se articulan diversos modos de comunicación en una red Interactiva, en hipertextos que integran por vez primera en la historia las modalidades escrita, oral y audiovisual (texto, imágenes y sonido) en el mismo sistema, interactuando desde puntos múltiples, en un tiempo elegido (real o demorado) a lo largo de una red global, con acceso abierto y asequible, cambiando radicalmente el carácter de la comunicación humana (Castells, 1999, p. 134).

Igualmente, en esta era, toma relevancia la educación. Educar es, de por sí, un proceso complejo. Tiene demasiadas aristas, perspectivas, mecánicas y metodologías; así como formas de entenderla, diseñarla y practicarla. Existen tantas prácticas pedagógicas como maestros en el mundo. Incluso conceptos como "maestro" y "profesor" ya dejaron de ser sinónimos en algunos espacios teóricos.

La educación y la comunicación se han encontrado en varios espacios, no solo en el aspecto teórico, sino práctico, ya que en varias teorías educativas se entiende que el proceso pedagógico es un modelo de comunicación, donde existe un emisor (docente) y un receptor (estudiante), además de un mensaje (tema) y un medio (aula de clase). 
Así surge un concepto revolucionario: la "educomunicación", entendida no solo como un vértice de encuentro, sino como una forma de evolución de ambos conceptos. La articulación de la educomunicación es innovadora, pero también desde otras aristas teóricas se abre un horizonte nuevo que merece ser profundizado. Dentro de este contexto, la academia contemporánea hace una introspección de su quehacer y replantea procedimientos, metodologías y didácticas.

\section{Transmedia y educación}

Desde los albores de la humanidad, se ha identificado la necesidad de medios que permitan la generación de mensajes que construyan y conformen las relaciones entre los sujetos. Desde la voz, hasta las nuevas plataformas de la información, los medios se han convertido en los componentes de la interacción social necesaria para la conformación de comunidad. Y precisamente es allí donde viene el concepto de comunicación: la construcción de mensajes que hacen posible la generación y conformación de relaciones entre sujetos activos de una sociedad.

Del anterior concepto, se deriva la formación de diferentes medios que permitan crear esa misma construcción, reconociéndose también a los medios tradicionales de comunicación, tales como la dialéctica, la tradición oral, las misivas y (con la creación de la imprenta) los medios escritos, que formaron más adelante los periódicos. Una evolución que se extendió casi tres siglos, permitiendo la conformación de los mass media como mecanismos de influencia, ya no de personas, sino de la misma sociedad.

Durante el siglo XX, se evidenciaron los grandes alcances y avances de los medios masivos de comunicación, como mecanismos de influencias en las masas. No obstante, en la última década del siglo XX, se comenzó a abrir espacio hacia una nueva revolución de la información y el conocimiento. La Internet resulta ser la plataforma que abarca un amplio margen de las sociedades, con una gran capacidad de permear en los diferentes estilos de vida.

En pocos años se pasó de la mediación a la multimedia, pasando al hipertexto, luego al crossmedia, llegando a la tendencia actual de la transmedia. Este recorrido (que se ha extendido durante tres décadas) describe la evolución 
de los medios digitales y su influencia en las realidades de las personas. La transmedia resulta ser el desarrollo de contenidos en diferentes medios. Por lo tanto, se define como la interacción del mensaje, con historias que producen recordación mediante la conformación de mensajes que propenden a generar una sola intención comunicativa. Así, la transmedia produce contenidos desde un solo canal, empleando diferentes medios donde converge una sola intención del mensaje.

En todo caso, la comunicación transmedia es mucho más que la adaptación de un mensaje en distintos medios y lenguajes: es el desarrollo de estrategias que desenvuelven un mundo narrativo

que abarca diferentes medios y lenguajes. De esta manera, el relato se expande, aparecen nuevos personajes o situaciones que traspasan las fronteras del universo de ficción. Esta dispersión textual encuentra en lo narrativo su hilo conductor (aunque sería más adecuado hablar de una red de personajes y situaciones que conforman un mundo) es una de las más importantes fuentes de complejidad de la cultura de masas contemporánea (Scolari, 2013).

Al trasladarse al contexto educativo, permite la aplicación de diversos medios que interactúan en el aula de clase con el claro propósito de generar mayor apropiación del conocimiento, mediante la interacción de todos los actores que intervienen en el proceso educativo.

En el 2015 se creó el proyecto europeo Transmedia Literacy ("alfabetismo transmedial") que profundiza en las competencias transmediáticas y las estrategias de aprendizaje informal, así como pautas para desarrollarlas dentro de las aulas ${ }^{1}$. El proyecto indaga sobre los hallazgos científicos relacionados con el consumo y producción transmediática, así como las estrategias de aprendizaje informal desarrolladas por los denominados nativos digitales. Los productos de investigación disponibles para todos en la web se componen de un

1. Este proyecto de investigación, liderado por Carlos Alberto Scolari, profesor del Departamento de Comunicación y coordinador del Grupo de Investigación MEDIUM (Barcelona, España) cuenta con la participación de 50 investigadores procedentes de Australia, Colombia, España, Finlandia, Italia, Portugal, Reino Unido y Uruguay. Ha comprometido un trabajo de campo integrado por 4500 cuestionarios, 58 talleres en el aula y 311 entrevistas con jóvenes entre 11 y 18 años. 
kit de actividades didácticas para aplicar las competencias transmediáticas de los estudiantes en sus clases. Además, se ofrece una guía de aplicación de transmedia (llamada "El libro blanco") y fichas didácticas online ("Kit del profesor". Ambos recursos se pueden descargar de forma gratuita en la web del proyecto Transmedia Literacy (https://transmedialiteracy.org/).

En esta metodología, el estudiante (además de ser un consumidor) es un productor de contenidos, por eso es denominado "prosumidor". Por su parte, el rol del docente es designado como "edupreneur", un gestor de historias ligadas entre sí, un administrador de contenidos pedagógicos coherentes en una sincronía narrativa o en una simbiosis "prosumidor / edupreneur" propia de una metodología de aprendizaje horizontal.

\section{Metodología}

\subsection{Fase 1}

El proyecto se desarrolló mediante un método de investigación mixto, para poder establecer resultados cualitativos y cuantitativos que midieran el impacto de las mediaciones pedagógicas transmediales. En primera instancia, en 2017 se realizó una encuesta a 80 estudiantes de estos programas, a fin de conocer sus percepciones acerca de las prácticas pedagógicas utilizadas por los docentes ${ }^{2}$.

En el año 2018, se realizó una serie de entrevistas a los docentes del área para conocer su percepción acerca de las prácticas pedagógicas que desarrollaban habitualmente. De manera paralela, se realizó un focus group con estudiantes para evaluar ese mismo tema.

Precisamente sobre la transmedia, se capacitó a los docentes, quienes desarrollaron piezas narrativas específicas relacionadas con el objetivo del proyecto. Se conformaron cuatro grupos de estudiantes: dos experimentales y dos de control. A los primeros se les presentaron metodologías pedagógicas tradicionales y a los segundos, didácticas transmediales. Finalmente, se hizo una prueba evaluativa ${ }^{3}$.

2. La mayoría no estaba satisfecha con las prácticas pedagógicas tradicionales. 


\subsection{Fase 2}

Con la finalidad de afianzar los procesos pedagógicos (para mejorar los resultados de los componentes específicos de la Prueba de Estado para todos los estudiantes de la Facultad de Comunicación) la Institución Universitaria Latina Unilatina (Bogotá, Colombia) buscó implementar la transmedia: entendiendo sus características y cómo puede transformar la práctica pedagógica, así como el conocimiento disciplinar de los estudiantes de la Facultad de Comunicación compuesta por los programas de Dirección y Producción de Radio y Televisión y de Publicidad.

\subsection{Fase 3}

El proceso metodológico se inició con la aplicación de una entrevista estructurada a los once docentes de la Facultad de Comunicaciones, que tuvo como objetivo diagnosticar las mediaciones pedagógicas actuales que se utilizaban en el desarrollo de sus actividades académicas. Se aplicó el método cualitativo, bajo la teoría fundamentada ${ }^{4}$, obteniéndose resultados numéricos susceptibles de análisis estadístico.

Los resultados de las entrevistas mostraron que los docentes usan mayormente las clases magistrales como sistema pedagógico tradicional, empleando fuentes documentales (libros e Internet), además del uso de diapositivas y recursos audiovisuales, para tratar temas más densos. La mayoría de los docentes conocen las nuevas técnicas pedagógicas asociadas al uso de recursos digitales y TIC para el desarrollo de estrategias pedagógicas.

Asimismo, los profesores reconocieron que deben mejorar sus prácticas, teniendo en cuenta que en las evaluaciones docentes (que realiza periódicamente la institución) se refleja la falta de didácticas que se conjuguen con nuevas

3. Los grupos experimentales obtuvieron resultados levemente mejores que los grupos control. Luego de las entrevistas a los estudiantes, se pudo observar una mayor aceptación de esta mediación pedagógica, que incluso los motivó a aprender y querer usar más estas herramientas.

4. Strauss \& Corbin (1994) afirman que la teoría fundamentada puede ser utilizada para un mejor entendimiento de un fenómeno ya estudiado y así poder profundizar en este. 
metodologías. Los docentes manifestaron haber escuchado el término "transmedia", pero lo confunden con "crossmedia", "multimedia" o "hipermedia".

Se decidió trabajar con dos docentes que tenían cursos en horarios diurnos y nocturnos, con mayor interés y disponibilidad para participar de las actividades metodológicas de esta propuesta. Los grupos de estudiantes de la jornada diurna (grupos de control) recibirían sus clases bajo técnicas tradicionales de pedagogía y los grupos de estudiantes de la jornada nocturna (grupos experimentales) recibirían sus clases bajo una mediación transmedial.

De manera paralela, se realizó un grupo focal con estudiantes para conocer sus percepciones sobre las mediaciones pedagógicas usadas por los docentes y desarrollar un estudio de opiniones o actitudes frente a la posibilidad de implementar prácticas pedagógicas innovadoras 5 .

Uno de los procesos más importantes que contribuyó con el logro de los objetivos fue el desarrollo de una capacitación docente que se realizó después de las actividades anteriormente descritas y que permitió permear (conceptual y estratégicamente) a los profesores participantes. Para esto, se decidió concentrar todos los contenidos a impartir en una página web diseñada para alojar videos, podcast de audio, lecturas, ayudas visuales y otras herramientas.

El objetivo de la capacitación consistió en caracterizar las narrativas transmediales que debían implementarse en el desarrollo de sus clases. En la primera jornada, se desarrolló un grupo de discusión sobre la conceptualización basada en el marco teórico del proyecto. En la segunda sesión, se realizó un taller transmedial, donde se abordaron técnicas para la realización de productos visuales, audiovisuales y sonoros. En la tercera y última sesión se desarrollaron las didácticas a aplicar por los docentes.

Uno de los docentes hizo uso de didácticas transmediales por medio de la producción de un programa de radio, una serie de videos y lecturas sobre el tema a tratar para su grupo experimental. El segundo docente hizo uso de un

5. Las preguntas iniciales fueron respondidas por la interacción del grupo en una dinámica en la que los participantes (de una manera sencilla y cómoda) aportaron ideas sobre cómo mejorar los procesos objeto de estudio. 
video, un podcast y una campaña publicitaria modelo, de igual forma para su grupo experimental.

Para la obtención de los resultados cuantitativos, se aplicaron las estrategias (desarrolladas por los docentes) a los cuatro grupos (dos de control y dos experimentales). A los grupos de control se les presentaron metodologías pedagógicas tradicionales y a los grupos experimentales, didácticas transmediales, como se explicó anteriormente. Es importante destacar que ambos grupos recibieron las mismas temáticas: fundamentos de radio y publicidad.

Al finalizar las clases, los docentes realizaron una evaluación, cuyos resultados mostraron que los grupos de control obtuvieron un $67 \%$ de respuestas correctas, frente a un $79 \%$ de respuestas correctas de los grupos experimentales, es decir este último, obtuvo un 12\% más respuestas correctas, como se podrá apreciar detalladamente en el apartado de resultados.

\subsection{Fase 4}

En esta última fase se buscó la aplicación de la estrategia en un contexto distinto, que permitiera reconocer la importancia de esta en un espacio diferente al que se venía llevando e identificar la apropiación de los conceptos desde la mediación transmedia del mensaje. Se concretó en la elaboración de contenidos transmedia como herramienta de difusión científica en la Universidad Sergio Arboleda.

\section{Resultados}

\subsection{Descripción de los hallazgos empíricos}

A los cuatro grupos se les hizo una prueba de conocimiento (20 preguntas), siendo los grupos experimentales los que mostraron mejores resultados, teniendo un promedio general superior que de los integrantes de los grupos de control.

El grupo de control 1 estuvo integrado por 12 estudiantes: cada uno contestó 20 preguntas, sumando un total de 240 respuestas. De estas, 150 respuestas fueron correctas y 90 incorrectas, obteniéndose una efectividad del $75 \%$ (figura 1). 
Figura 1: Resultados globales del grupo de control 1.

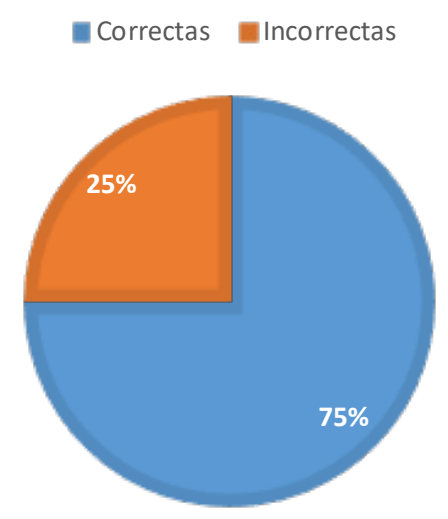

Fuente: Elaboración propia.

El grupo experimental 1 estuvo integrado por 11 estudiantes: cada uno contestó 20 preguntas, sumando un total de 220 respuestas. De estas, 170 respuestas fueron correctas y 50 incorrectas, obteniéndose una efectividad del $77 \%$ (figura 2).

Figura 2: Resultados globales del grupo experimental 1.

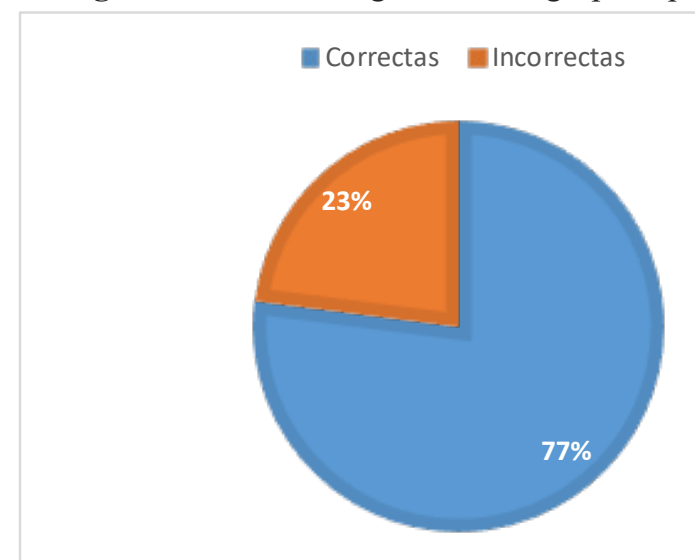

Fuente: Elaboración propia.

El grupo de control 2 estuvo integrado por 12 estudiantes: cada uno contestó 20 preguntas, sumando un total de 240 respuestas. De estas, 150 respuestas fueron correctas y 90 incorrectas, obteniéndose una efectividad del 71 \% (figura 3). 
Figura 3: Resultados globales del grupo de control 2.

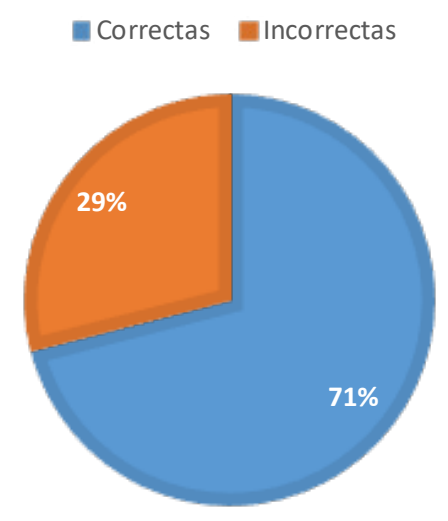

Fuente: Elaboración propia.

El grupo experimental 2 estuvo integrado por 15 estudiantes: cada uno contestó 20 preguntas, sumando un total de 300 respuestas. De estas, 240 respuestas fueron correctas y 60 incorrectas, obteniéndose una efectividad del $80 \%$ (figura 4).

Figura 4: Resultados globales del grupo experimental 2.

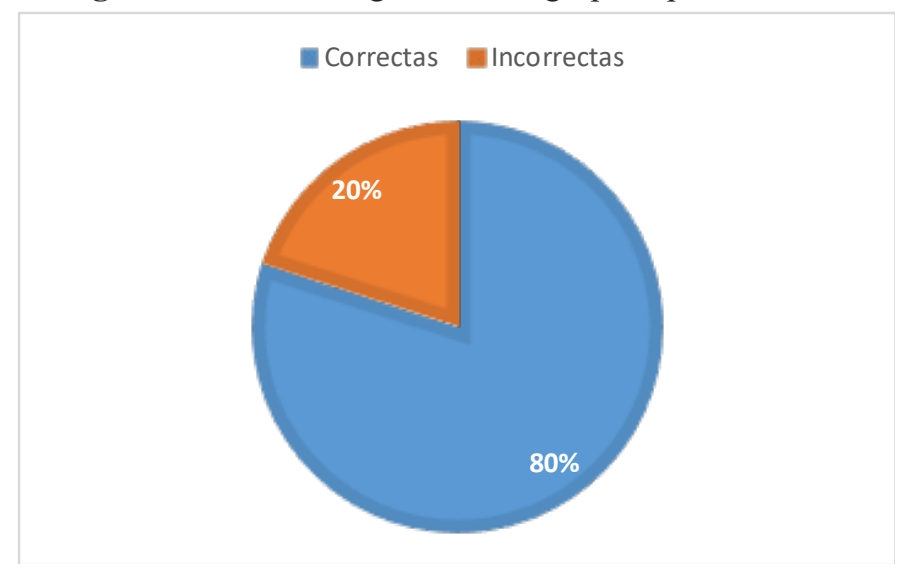

Fuente: Elaboración propia.

\subsection{Análisis de la información}

Las prácticas pedagógicas en la era tecnológica contemporánea han empezado a reevaluarse. La inexorable irrupción de la tecnología en las aulas de 
clase ha revolucionado el quehacer de los docentes. Hoy en día, las múltiples páginas web y aplicaciones han reemplazado, o por lo menos desplazado, las bibliotecas, las enciclopedias y los textos se han convertido en digitales.

El usuario de las nuevas tecnologías no solo las recibe, sino también las crea, además puede decidir que recibe, que descarta o que profundiza: "generación, procesamiento y transmisión [...] se convierten en las fuentes fundamentales de productividad y poder" (Castells, 1999, p. 56). Incluso se puede afirmar que quien "tiene la información puede o tiene la posibilidad de decidir pues se ve que la información, medio eficaz para la globalización, es un instrumento o una herramienta valiosísima en términos del ejercicio y práctica del poder; ella otorga el poder a quien la posee y domina" (Arias, 2007).

Hinojo \& Fernández (2012) sostienen que la capacidad de incorporar las TIC a la educación "no sólo da más posibilidades de acercar conocimientos a más lugares y personas salvando distancias; supone además una innovación en la educación, pues al existir más posibilidades, el aprendizaje se ve modificado en comparación con una enseñanza más tradicional”.

Por lo anterior, los resultados del proyecto reafirmaron que una mediación pedagógica actualizada (que haga uso de las TIC) mejora la relación docente-estudiante, base de la educación contemporánea. Una de las dificultades que existen ahora se basa en la dificultad de establecer herramientas pedagógicas coherentes y concisas. Desde esa perspectiva, vale la pena mencionar que las prácticas pedagógicas, basadas en narrativas transmedia, pueden ser altamente eficaces.

Por otra parte, en los objetivos del proyecto se planteó, en síntesis, la necesidad de diagnosticar, diseñar y evaluar la mediación pedagógica, basada en la narrativa transmedia donde se encuentra un espacio específico para la creación de nuevos espacios de fortalecimiento pedagógico, que en el futuro deben ser aprovechados por las nuevas generaciones de estudiantes ávidos de información y de canales comunicativos con los cuales se puede reforzar los temas de aprendizaje.

Ahora bien, contrastando otras posturas teóricas planteadas en el proyecto, se puede observar que, desde el punto de vista de la comunicación, Castells (1999) veía en la Internet un eje del sistema de comunicación global moder- 
no, enmarcado en la sociedad de la información, contrastado con Calvelo (1988), quien se refirió a la comunicación como un proceso por medio del cual los mensajes deben ser convenidos con todos los que intervengan en el diálogo de comunicación, para que los mensajes estén acordes con las necesidades reales del receptor.

Desde el punto de vista de la pedagogía, como se mencionó en el apartado teórico, el proceso de aprendizaje traspasa los espacios escolares; el proceso de enseñanza-aprendizaje incluye todo un cúmulo de percepciones entre los sujetos activos del proceso para que los estudiantes aprendan el conocimiento aprendido: "la actuación del profesor es determinante en su proceder y crecimiento intelectual" (Covarrubias \& Piña, 2004).

Significa esto, a la luz de este proyecto, que el docente se convierte en un mediador de información, un motivador que abre espacios de interacción para que sea el estudiante quien continúe ese camino y consolide el proceso. Alpízar (2002) considera la escuela como un lugar de diversidad y confluencia. La experiencia descrita en este proyecto demuestra que existe interés de los estudiantes de Unilatina en la configuración de la academia con un espacio de encuentro y de articulación de diferentes formas de pensamiento, pero además de creación de conocimiento. Se puede profundizar en este aspecto con López (2014):

Entendemos a los profesores como sujetos activos, reflexivos, capaces de tomar decisiones fundamentadas a la hora de enseñar. Es aquí donde se inscribe el concepto de estrategia de enseñanza, otorgándole al profesor la capacidad de tomar decisiones sobre su propia práctica.

En el proyecto, mediante la capacitación a los docentes de Unilatina, se reforzó la presencia de la tecnología en el uso de nuevas estrategias pedagógicas. Si bien sólo dos docentes hicieron parte de la fase experimental, en una primera instancia todos los profesores del área contactados aceptaron la importancia de la tecnología y la necesidad de establecer nuevas mecánicas y didácticas, entendiendo que el estudiante actual se ha formado dentro del mundo tecnológico y el marco común debe ser la misma base tecnológica. Así también, coincidieron en aceptar que debe haber un uso mayor de herramientas digitales y que la actualización tecnológica debe darse todo el tiempo para adaptarse al mundo digital contemporáneo. 
Por lo anterior se debe reconocer que están en declive los paradigmas que refieren un conocimiento producto de la comunicación unidireccional, puesto que ahora pasa a ser multidireccional.

La construcción colectiva del conocimiento como el proceso donde dos o más personas (educandos y maestros) tienen la posibilidad de intercambiar experiencias y conocimientos, con el único fin de obtener un nivel más elevado de comprensión de la realidad, de lo que tenían anteriormente (Alpízar, 2002).

Los indicadores encontrados permiten describir la necesidad latente de articular la tecnología, la creación de contenidos, la sinergia entre los actores involucrados en el proceso, en una didáctica pedagógica innovadora y necesaria, teniendo en cuenta que la nueva generación de estudiantes son nativos digitales que están en permanente contacto con la tecnología y los medios.

Asimismo, se establece que existe una relación directa del uso de las narrativas transmedia con los objetivos del proceso pedagógico: la apropiación de conocimiento a partir de su co-creación. En consecuencia, se debe motivar al docente a fomentar la construcción aprehensiva del mismo, mediante la acción de motivar al estudiante a convertirse en prosumidores, en agentes activos del proceso, apartándose del modelo antiguo de educación.

Es necesario introducir el uso de los lenguajes audiovisuales, de la informática, de los ordenadores y de los nuevos medios. Una escuela consciente, y que responda a las exigencias de nuestro tiempo, no puede renunciar a esta tarea (Pérez Tornero, 2000).

Las mediaciones pedagógicas son parte de un marco de didácticas pedagógicas que motivaban los espacios de diálogo y contexto social buscando la re-significación: entender que la educación evoluciona, así como los medios usados para el proceso enseñanza-aprendizaje. Se estableció un contexto donde los actores comunicativos podían expresar sus perspectivas sobre la necesidad de la inclusión de la transmedia en los procesos participativos de la educomunicación.

Los aspectos descritos demuestran la viabilidad del uso de la comunicación en los procesos pedagógicos, por lo que es necesario concientizar a los docentes en la necesidad de crear nuevas didácticas pedagógicas. Además, se 
debe capacitar a los docentes en las narrativas transmedia, su diseño y construcción de contenidos; su articulación de medios y mensajes y su respectiva evaluación. Por lo anterior, es conveniente concertar con padres, profesores y estudiantes estas mecánicas para poder establecer unas normas de comunicación-educación propias del mundo contemporáneo.

De igual forma, se puede evidenciar que la educomunicación es una herramienta útil para el aprovechamiento de las relaciones que existen entre estudiantes y profesores, por lo que se pueden aprovechar distintas maneras pedagógicas que permitan entender que la educación es un proceso comunicativo que propende por la puesta en común de espacios, de integrar el mundo del estudiante con el del docente, de crear un código común entre ambos, un lenguaje similar y un objetivo común. Unir dos mundos es el primer paso para un proceso pedagógico exitoso.

Encontrar soluciones en los entornos en los que vivimos (para generar una conciencia social) es entender que las mismas sociedades deben optimizar sus condiciones de vida, dentro de los marcos sociales, económicas y culturales. Entender las dificultades y los avances son indispensables para renovar la sociedad.

En todo caso, esta mediación puede resultar afectada por el uso indiscriminado de la tecnología y las redes sociales: se deben fijar normas para el uso de dispositivos y herramientas digitales, a fin que produzcan un impacto verdaderamente positivo y que ayude al desarrollo de cada individuo. La generación de la cultura debe partir de la necesidad de encontrar nuevas luces hacia el futuro de la tecnología y la educación.

Ha sido tal el cambio, que ahora no es una excepción, sino una regla, el uso de las estrategias comunicativas en la academia en cualquier nivel de formación; sin embargo, ahora las aulas se enfrentan a las nuevas tecnologías y pese a que los mismos medios tradicionales están librando su propia batalla para poder superar este nuevo auge comunicacional, la academia todavía no termina de comprender las potencialidades de la tecnología como un valor agregado para la transmisión y apropiación del conocimiento. Tampoco debe entenderse el uso de las nuevas tecnologías como una estrategia transmedial propiamente dicha, ni mucho menos creer que es el modelo utópico que viene a resolver las falencias educativas que han pasado de generación en generación. 
Esto refuerza el concepto de Prieto et al., citado por Díaz (2013), cuando conjugan los términos "educación” y "comunicación" cuando afirman que

desde lo educativo, se concibe la pluralidad de prácticas de aprendizaje, pedagógicas y didácticas mediante las cuales se configuran procesos educomunicativos en una multiplicidad de escenarios que van desde los ámbitos interpersonales cotidianos, pasando por los espacios formales de las instituciones educativas, hasta los complejos procesos de inter-aprendizaje que se gestionan a través de los medios masivos y las redes y entornos digitales.

El objetivo está en la formación de profesionales con un sentido mucho más amplio en términos de ética, uso y apropiación del conocimiento. Es una obligación de la academia estar a la altura del reto, saber que algunos estudiantes tienen conocimientos que pueden complementarse con los del docente y que juntos forman una fuerza diferente que está lista para reinventar, a diario, los cánones de la pedagogía, sin que esto signifique conocimiento superfluo.

Décadas atrás, las fuentes de educación eran contadas, o por lo menos el acceso a estas no era tan amplio. Los libros en las bibliotecas no eran suficientes en algunos temas, por ejemplo, en lo que se refiere a número de ejemplares. El copiado de páginas por medios mecánicos era una rutina. Los estudiantes podían acumular bibliotecas enteras de copias mecánicas a blanco y negro. En nuestros días, la tecnología ha casi que acabado con ese mecanismo. Difundir un archivo PDF por correo o por otros medios es una práctica frecuente. Incluso el uso del CD-ROM se ha ido olvidando, desplazando hacia el uso de envío de correo, memorias de conexión USB o el uso de plataformas de almacenamiento en la nube.

Desde un punto de vista educativo, estamos ante un proceso de intercambio comunicativo que permite no sólo la interacción entre las partes, sino la retroalimentación y el diálogo horizontal que conlleva a un proceso social incluyente, participativo y sostenible. En este aspecto, la UNAD sostiene que la comunicación es un proceso mediador "situado e interactivo con características que sustentan el aprendizaje y que fortalecen las competencias cognitivas, las socio-afectivas y las operativas de los sujetos" (Díaz, 2013).

Esto hace que las copias impresas almacenadas (que luego eran pasto del reciclaje) queden relegadas por cientos de MB archivadas. Así, el docente debe 
dejar de ser un transmisor de información, un simple canal por el que circula la información, para transformarse en un guía que permita encontrar la información oportuna, suficiente y necesaria para comprender un tema cualquiera.

Todos los instrumentos desde la pizarra, el libro, el compás, eran instrumentos físicos reales, hoy en día la tecnología nos permite crear un laboratorio de física virtual, nos permite simular instrumentos, por lo que ya no es tan difícil distribuir los materiales didácticos. Trabajaremos con medios virtuales, con medios compartidos, con medios descentralizados. Y si las redes de telecomunicaciones de un país antes eran para difusión, hoy día son de doble vía de contacto e interacción. Si las fuentes o las redes nos permiten el paso de lo estático a lo móvil ¿será posible establecer un sistema de tutoría en línea, donde los alumnos consulten vía Internet a un grupo de profesores, por ejemplo, para saber cómo resolver un problema? De hecho, este sistema ya es una realidad (Pérez Tornero, 2000).

Esta propuesta, aunque parta de las aulas de Unilatina, puede ser ampliada a muchos otros espacios y escenarios, lo que garantiza aún más su valoración que permitiría mejorar la calidad de la educación impartida en Bogotá, así como en otras capitales latinoamericanas.

La academia debe explotar este medio para llegar de mejor forma a los estudiantes e incentivarlos a apropiarse del conocimiento; considerarlos sujetos eminentemente activos en este proceso educativo que cada vez, con mayor fuerza, tiene un referente de acción social del conocimiento, puesto que este no se construye entre las fronteras de acero y concreto de la academia, sino que va mucho más allá. Es aquí donde la transmedia no es una herramienta para el futuro de la educación, sino que es un modelo educativo para nuestros días.

\section{Fuentes consultadas}

Alpízar, J. (2002). Educación y aprendizaje. San José de Costa Rica: Impresora Obando.

Arias, F (2007). Educación en la globalización: un cambio en la perspectiva. Revista Latinoamericana de Ciencias Sociales, Niñez y Juventud, 5(1). Recuperado de https://www.redalyc.org/pdf/773/77350103.pdf 
Calvelo, M. (1988). El video-educativo rural. En Acevedo, J. et al., Educación y comunicación popular en el Perú (pp. 103-110). Lima: DESCO-IPAL.

Castells, M. (1999). La era de la información. La sociedad red (vol. 1). México, DF: Siglo XXI.

Covarrubias, P. \& Piña, R. (2004) La interacción maestro-alumnos y su relación con el aprendizaje. Revista Latinoamericana de Estudios Educativos, XXXIV(1). Recuperado de: http://www.redalyc.org/articulo. oa? id=27034103

Díaz Téllez, A. (2013). Aproximación a la noción de educomunicación, caso del diseño de la maestría en comunicación de la Universidad Nacional Abierta y a Distancia. Pangea. Revista de la Red Iberoamericana de Comunicación, 4(1), 212-228. Recuperado de: http://revistaraic.files. wordpress.com/2013/10/04-01-13-dc3adaz-tc3a91lez-212-a-228.pdf

Hernández Sampieri, R., Fernández Collado, C. \& Baptista Lucio, M. (2008). Metodología de la investigación. México, DF: McGraw-Hill. Recuperado de https://www.uca.ac.cr/wp-content/uploads/2017/10/Investigacion.pdf

Hinojo, M. \& Fernández, A. (2012). El aprendizaje semipresencial o virtual: nueva metodología de aprendizaje en Educación Superior. Revista Latinoamericana de Ciencias Sociales, Niñez y Juventud, 10(1), 159-167. Recuperado de http://www.redalyc.org/pdf/773/77323982008.pdf

López, S. (2014). Estrategia de enseñanza, hacia la narrativa digital transmedia en el aula virtual. Buenos Aires: Universidad Nacional de Educación a Distancia.

Martín-Barbero, J. (2000). Retos culturales de la comunicación en la educación. Revista Chilena de Temas Sociológicos, IV(6-7).

Pérez Tornero, J. (2000). El desarrollo de la sociedad de la información: del paradigma de la cultura de masas al de la cultura multimedia. En J. Pérez Tornero (Coord.), Comunicación y educación en la sociedad de la información. Barcelona: Paidós. 
Scolari, C. (2013). Narrativas transmedia. Cuando los medios cuentan. Barcelona: Deusto.

Strauss, A. \& Corbin, J. (1994). Bases de la investigación cualitativa. Técnicas y procedimientos para desarrollar la teoría fundamentada. Recuperado de https://diversidadlocal.files.wordpress.com/2012/09/ bases-investigacion-cualitativa.pdf

Valdés, A., Angulo, J., Urías, M., García, R. \& Mortis, S. (2011). Necesidades de capacitación de docentes de educación básica en el uso de las TIC. Pixel-Bit. Revista de Medios y Educación, 39, 211-223. 